ARTICLE

Received 15 Apr 2015 | Accepted 11 Nov 2015 | Published 10 Dec $2015 \quad$ DOl: 10.1038/ncomms10163 OPEN

\title{
Presynaptic hyperpolarization induces a fast analogue modulation of spike-evoked transmission mediated by axonal sodium channels
}

Sylvain Rama ${ }^{1,2,3, \star}$, Mickaël Zbili,2,3,* , Andrzej Bialowas ${ }^{1,2,3}$, Laure Fronzaroli-Molinieres ${ }^{1,2,3}$, Norbert Ankri ${ }^{1,2,3}$, Edmond Carlier ${ }^{1,2,3}$, Vincenzo Marra ${ }^{1,2,3} \&$ Dominique Debanne $e^{1,2,3}$

In the mammalian brain, synaptic transmission usually depends on presynaptic action potentials (APs) in an all-or-none (or digital) manner. Recent studies suggest, however, that subthreshold depolarization in the presynaptic cell facilitates spike-evoked transmission, thus creating an analogue modulation of a digital process (or analogue-digital (AD) modulation). At most synapses, this process is slow and not ideally suited for the fast dynamics of neural networks. We show here that transmission at CA3-CA3 and L5-L5 synapses can be enhanced by brief presynaptic hyperpolarization such as an inhibitory postsynaptic potential (IPSP). Using dual soma-axon patch recordings and live imaging, we find that this hyperpolarization-induced AD facilitation ( $h-A D F$ ) is due to the recovery from inactivation of Nav channels controlling AP amplitude in the axon. Incorporated in a network model, h-ADF promotes both pyramidal cell synchrony and gamma oscillations. In conclusion, cortical excitatory synapses in local circuits display hyperpolarization-induced facilitation of spike-evoked synaptic transmission that promotes network synchrony.

\footnotetext{
${ }^{1}$ INSERM, UMR_S 1072, Faculté de Médecine Secteur Nord, Boulevard Pierre Dramard, Marseille 13344, France. ${ }^{2}$ UNIS, Faculté de Médecine Secteur Nord, Boulevard Pierre Dramard, Marseille 13344, France. ${ }^{3}$ Aix-Marseille University, 13015 Marseille, France. * These authors contributed equally to this work. Correspondence and requests for materials should be addressed to D.D. (email: dominique.debanne@univ-amu.fr).
} 
$\mathrm{N}$ euronal information in the mammalian brain is generally transmitted through spike-evoked packets of neurotransmitter in a digital mode of signalling. It has been recently shown, however, that subthreshold analogue activity in the presynaptic element might modulate this digital signalling, leading to the emergence of the concept of a hybrid analogue-digital (AD) facilitation of synaptic transmission. Initially described in invertebrates $^{1-4}$, this $\mathrm{AD}$ facilitation has been reported in many mammalian synapses including cortical ${ }^{5-7}$, cerebellar ${ }^{8,9}$ and hippocampal synapses ${ }^{10-13}$. This $\mathrm{AD}$ facilitation is induced by depolarization of the presynaptic neuron and is mediated by an elevation of glutamate release $6,9,14$. There are two independent mechanisms accounting for AD facilitation today ${ }^{15}$ : (i) inactivation of D-type $\mathrm{K}^{+}$channels ${ }^{6,13,16,17}$ and (ii) elevation in basal $\mathrm{Ca}^{2+}$ concentration mediated by the opening of $\mathrm{P} / \mathrm{Q}$-type voltage-gated $\mathrm{Ca}^{2+}$ channels ${ }^{8,9,14}$. Both forms of $\mathrm{AD}$ facilitation are slow processes because the underlying biophysical mechanism (inactivation of the D-type current or accumulation of $\mathrm{Ca}^{2+}$ in the axon) requires presynaptic voltage shifts lasting several seconds. Thus, these forms of AD modulation are not well suited for the fast network dynamics.

Analogue modulation by resting membrane potential is not limited to voltage-gated $\mathrm{K}^{+}$and $\mathrm{Ca}^{2+}$ channels. In fact, a large fraction of the axonal voltage-gated $\mathrm{Na}^{+}$(Nav) current is inactivated at the resting membrane potential ${ }^{18-20}$. The physiological consequence of Nav channel inactivation on axonal spike amplitude and synaptic transmission has not been clearly defined.

We show here that fast physiological hyperpolarization before the presynaptic action potential (AP) facilitates synaptic transmission in hippocampal and neocortical synaptic circuits. This hyperpolarization-induced $\mathrm{AD}$ facilitation (h-ADF) is due to the recovery of $\mathrm{Nav}$ channels from inactivation, thus enhancing the spike amplitude in the axon. Axonal recordings from L5 pyramidal neurons indeed revealed that hyperpolarization of the cell body specifically increased the spike amplitude in the axon but not in the cell body. The presence of $\mathrm{h}-\mathrm{ADF}$ in different areas of the brain indicates that this form of plasticity can be generalized to a wide range of cortical excitatory synapses. A major physiological interest of this form of $\mathrm{AD}$ facilitation is its fast kinetics. h-ADF produced by inhibitory postsynaptic potential (IPSP)-spike sequences not only facilitates synaptic strength across pyramidal cells but also enhances synchrony and gamma oscillations in a network model. Thus, interneurons paradoxically enhance excitatory transmission between pyramidal neurons and subsequently structure network dynamics.

\section{Results}

Hyperpolarization-induced AD facilitation. We first measured the incidence of brief hyperpolarization of the presynaptic cell on synaptic transmission. Pairs of monosynaptically connected CA3 neurons were recorded in organotypic cultures of the rat hippocampus after 8-10 days in vitro (DIV) ${ }^{21}$. A 200-ms hyperpolarizing pre-pulse delivered before the presynaptic spike was found to increase synaptic strength by $\sim 20 \%$ (Fig. 1a). This increase was observed when measuring either amplitude or charge of the postsynaptic response (Supplementary Fig. 1). In these experiments, the presynaptic resting potential was $-74 \pm 3 \mathrm{mV}(n=10)$. The h-ADF was comparable when the presynaptic hyperpolarization amounted to -84 or $-102 \mathrm{mV}$ (respectively, $124 \pm 8 \%$ versus $119 \pm 5 \%, n=10$; Wilcoxon test $P>0.1$, suggesting that a presynaptic hyperpolarization of $\sim 10 \mathrm{mV}$ is sufficient to obtain saturating h-ADF. h-ADF was associated with a reduced paired-pulse ratio (PPR, from $99 \pm 7$ to
$88 \pm 5 \%, n=12$; Wilcoxon test $P<0.05$; Supplementary Fig. 1 ), indicating that it results from a presynaptic increase in glutamate release.

A 200-ms-long hyperpolarization is unlikely to occur in a physiological context. Therefore, we investigated the time course of h-ADF for shorter hyperpolarizations (15, 50, 100 and $200 \mathrm{~ms}$ ). h-ADF was observed for all the durations of hyperpolarization tested (15 ms: $111 \pm 3 \%$, $50 \mathrm{~ms}: 116 \pm 4 \%$, $100 \mathrm{~ms}: 109 \pm 4 \%$, $200 \mathrm{~ms}: 120 \pm 6 \%$ Wilcoxon, $P<0.05$ for all durations, $n=7$, Fig. 1b). According to this result, h-ADF is likely to be induced by physiological hyperpolarization.

CA3 pyramidal neurons express depolarization-induced AD facilitation (d-ADF) that results from the slow inactivation of Kv1.1 channels (time constant: $3.3 \mathrm{~s})^{13}$. We thus examined whether both $\mathrm{d}$ - and h-ADF were expressed at the same CA3-CA3 connections. Presynaptic APs were triggered alternatively from resting membrane potential $(-78 \mathrm{mV}$ control), after a long subthreshold depolarization (10 s, $-62.6 \mathrm{mV}, \mathrm{d}-\mathrm{ADF})$, after a brief hyperpolarization $(200 \mathrm{~ms}$, $-96.1 \mathrm{mV}$, h-ADF) or after the combination of a long depolarization and a brief hyperpolarization (d- and h-ADF; Fig. 1c, left). In fact, the combination of the two forms of ADF produced, in the same connections, a greater facilitation $(113 \pm 3 \%, n=16$; Fig. 1c) than that produced separately by each protocol (d-ADF alone: $105 \pm 3 \%, n=16$, h-ADF alone: $108 \pm 4 \%, n=11$; Fig. 1c). Notably, averaged h- and d-ADF were found to summate linearly, suggesting two independent molecular mechanisms. Moreover, $\mathrm{d}-$ and $\mathrm{h}-\mathrm{ADF}$ measured in the same pairs were positively correlated (Supplementary Fig. 1), suggesting that some synaptic connections are more susceptible to $\mathrm{AD}$ facilitation, probably because analogue signal propagation along the axon depends on the distance between the soma and the presynaptic terminals. These data demonstrate that $h$ - and d-ADF coexist in CA3 pyramidal neurons and that the underlying mechanisms are likely to be independent.

$\mathrm{h}-\mathrm{ADF}$ was observed in young CA3 neurons (DIV8-10 prepared from $\mathrm{P} 5-\mathrm{P} 7$ rats), and thus it could mainly result from the low density or immature properties of voltage-gated ion channels. We therefore determined whether h-ADF was also found in mature CA3 pyramidal cells. Paired recordings of connected CA3 neurons were obtained in DIV24-DIV32 slice cultures. Brief presynaptic hyperpolarization $(200 \mathrm{~ms})$ significantly increased synaptic strength $(104.2 \pm 1.1 \% n=25$; Wilcoxon, $P<0.01$; Supplementary Fig. 2). h-ADF measured in mature cells was smaller from that measured in developing neurons (Mann-Whitney, $P<0.01$; Supplementary Fig. 2). We therefore conclude that $\mathrm{h}-\mathrm{ADF}$ is developmentally regulated in CA3 neurons in vitro.

All recordings were obtained with high extracellular calcium $(3 \mathrm{mM})$ to optimize synaptic strength. Under these conditions, presynaptic release probability is high and presynaptic facilitation such as h-ADF could be underestimated. We therefore measured h-ADF in mature CA3 neurons (DIV24-DIV32) recorded with physiological extracellular calcium $(1.3 \mathrm{mM})^{22}$. Under these conditions, h-ADF was found to be around $+16.4 \%$ (Wilcoxon, $P<0.01$; Supplementary Fig. 2). We conclude that $\mathrm{h}-\mathrm{ADF}$ is robustly expressed in mature neurons recorded in physiological extracellular calcium.

h-ADF is induced by simulated IPSPs and oscillations. To investigate the role of $\mathrm{h}-\mathrm{ADF}$ under near-physiological conditions, a $\mathrm{GABA}_{\mathrm{A}}$-like conductance was introduced in the presynaptic neuron using dynamic clamp (Fig. 2a, left). In agreement with results illustrated in Fig. 1, APs preceded by the injection of an IPSC-like current produced a larger response in the postsynaptic neuron compared with APs triggered from 
a

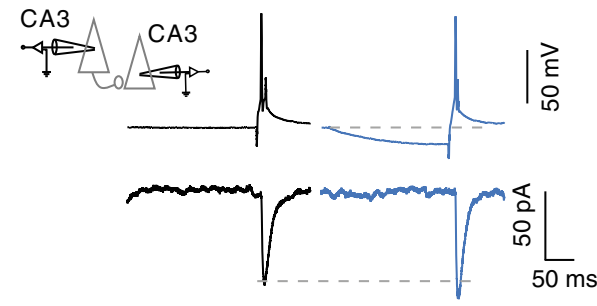

b

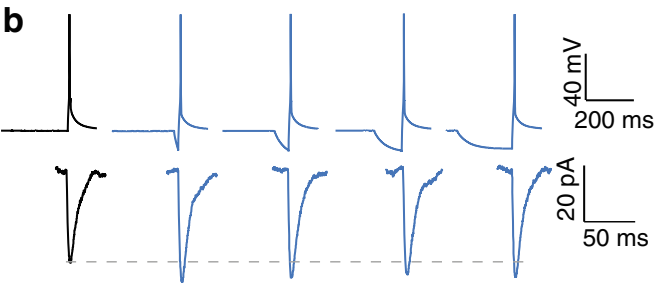

C

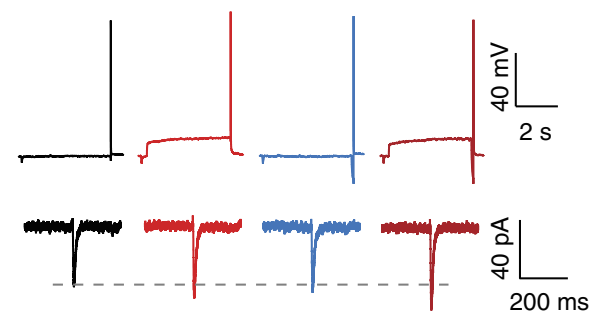

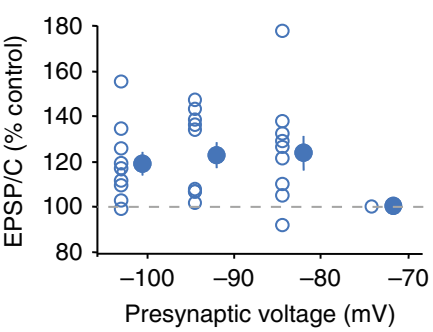
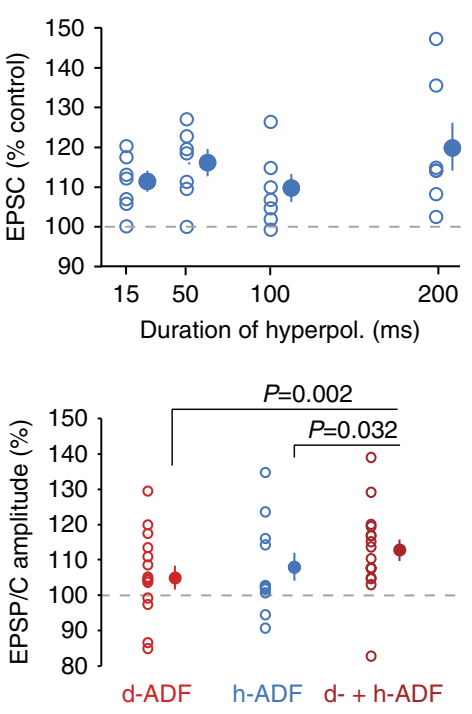

Figure 1 | Synaptic facilitation induced by transient hyperpolarization (h-ADF) in CA3 neurons. (a) Facilitation of synaptic transmission at CA3-CA3 connections by a hyperpolarizing pre-pulse ( $200 \mathrm{~ms}$ duration). Left, schematic of the recording configuration. Middle, example of facilitation produced by the presynaptic hyperpolarizing pulse (10 traces were averaged). Right, summary of facilitation induced by presynaptic hyperpolarization of increasing amplitude. Note that no further facilitation was induced when the magnitude of the hyperpolarizing pre-pulse was increased. (b) h-ADF can be induced by brief presynaptic hyperpolarization. Left, examples of recording from a pair of connected CA3 pyramidal neurons with no hyperpolarization and 15, 50, 100 and $200 \mathrm{~ms}$ of hyperpolarization to $-93 \mathrm{mV}$ before the spike. Right, summary of facilitation induced by 15, 50, 100 and $200 \mathrm{~ms}$ (all Wilcoxon test, $P<0.05, n=7$ ). (c) d- and h-ADF are coexpressed at CA3-CA3 connections. Left, representative example. Top traces, membrane potential of the presynaptic neuron in control (black), during d-ADF (red), during h-ADF (blue) and when d- and h-ADF are combined (dark red). Bottom traces, postsynaptic responses in each case averaged over 10 trials. Right, group data (Mann-Whitney test, $n=16$, for $d-A D F, 11$ for $h-A D F$ and 16 for $d-$ and h-ADF). Note the stepwise increase in transmission when $d-$ and h-ADF are combined.

resting membrane potential (Wilcoxon $P<0.001, n=11$ ). Consistent with a presynaptic elevation in glutamate release, the PPR was reduced when simulated GABAergic IPSPs preceded APs (from $121 \%$ in control to 96\%; Wilcoxon $P<0.05, n=7$; data not shown). Interestingly, the size of the synaptic potentiation was found to be dependent on the size of the simulated IPSP $\left(R^{2}=0.39, \quad P<0.05\right)$, indicating that $\mathrm{h}-\mathrm{ADF}$ is graded between resting membrane potential $(-74 \mathrm{mV})$ and 10-mV hyperpolarization ( $-84 \mathrm{mV}$; Fig. $2 \mathrm{a}$, right). In fact, the facilitation factor in this range was found to be $1.8 \%$ per $\mathrm{mV}$ of hyperpolarization.

We next investigated the modulation of synaptic strength during presynaptic membrane potential oscillation. Oscillation of the presynaptic membrane potential at $4 \mathrm{~Hz}$ was produced by injecting sinusoidal current, and single presynaptic spikes were evoked at different phases of the oscillation. In agreement with the previous results, h-ADF was observed when the cell fired during hyperpolarizing phases of the oscillation (0 ms: $124.3 \pm 7 \%, 250 \mathrm{~ms}: 122 \pm 7 \%$, Wilcoxon $P<0.05, n=8$; Fig. 2b). At other phases, the synaptic strength is unchanged (56 ms: $112.2 \pm 6 \%, 163 \mathrm{~ms}$ : $95.8 \pm 5 \%$, $211 \mathrm{~ms}: 110.5 \pm 6 \%$, Wilcoxon $P>0.1, n=8$ ). In particular, no $\mathrm{d}-\mathrm{ADF}$ is observed with the depolarization because its duration is too short to inactivate Kv1.1 channels ${ }^{13}$. We conclude that oscillations in the $\theta$ range induce h-ADF in CA3 neurons.
h-ADF is associated with an increase in axonal spike amplitude. Next, we investigated the mechanisms underlying h-ADF. A possible mechanism for $h-A D F$ is a modulation of the presynaptic spike amplitude induced by the hyperpolarization. We therefore examined the consequence of hyperpolarization on the spike amplitude measured in the axon. CA3 neurons were filled with Alexa $488(50 \mu \mathrm{M})$ to visualize the axon arborization, and cell-attached recordings were obtained from the axon at distances ranging between 60 and $240 \mu \mathrm{m}$ (Fig. 3a). On somatic hyperpolarization, the amplitude of the axonal spike was enhanced ( $106 \pm 1 \%$ of the control amplitude, $n=6$, Wilcoxon, $P<0.05$; Fig. 3b). However, the magnitude of axonal spike facilitation was found to decrease with the axonal distance with a space constant of $212 \mu \mathrm{m}$ (Fig. 3b). In conclusion, h-ADF in CA3 neurons is associated with a local increase in spike amplitude in the axon.

While whole-cell recording from CA3 axons is extremely difficult in organotypic cultures, it can be obtained in L5 pyramidal neurons from acute slices 5,6 . Therefore, we first measured whether h-ADF could be also observed at L5-L5 excitatory connections. Pairs of monosynaptically connected L5 pyramidal neurons were recorded in acute slices from the sensori-motor cortex of young rats (P14-P20). Brief hyperpolarization in the soma $(200 \mathrm{~ms}, 10-15 \mathrm{mV})$ of the 
a

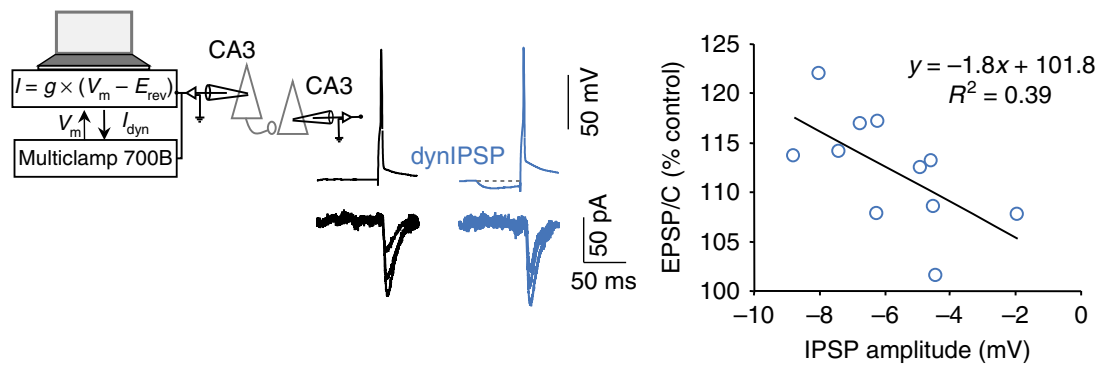

b
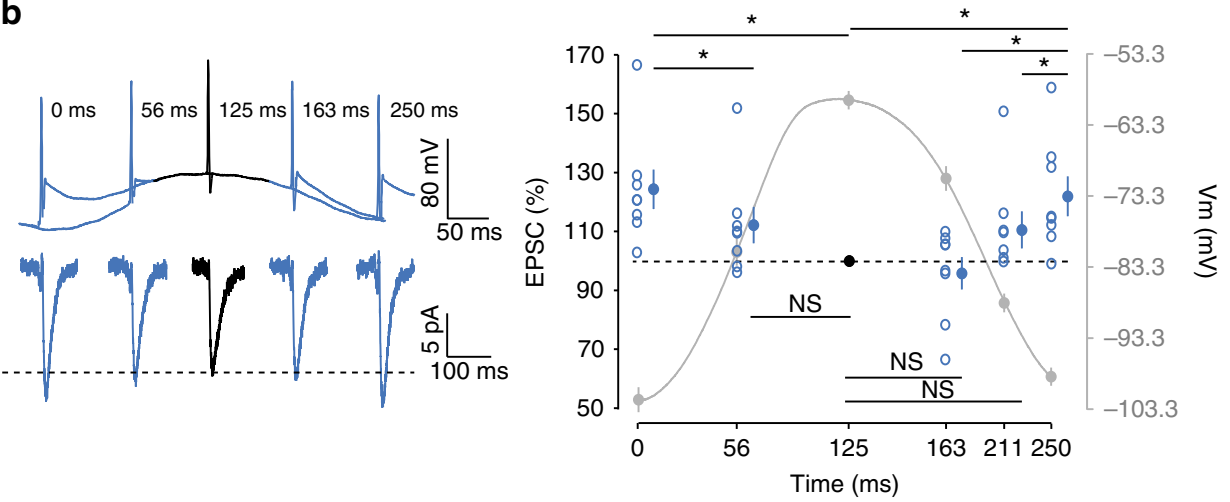

Figure 2 | Physiological induction of h-ADF. (a) Presynaptic IPSPs induce h-ADF. Left, schematic representation of the system used to inject a dynamic current mimicking a GABAergic input in the presynaptic neuron. Middle, examples of electrophysiological recordings from a connected pair of CA3 neurons in control conditions (black traces) and when a simulated GABAergic input is injected into the presynaptic cell (blue traces). Right, scatter plot showing the normalized EPSP/C as a function of the peak value of the simulated presynaptic IPSP. A clear linear correlation was observed $(y=-1.8 x+101.8$, Pearson's $\left.R^{2}=0.39, P<0.05, n=11\right)$. (b) $h$-ADF induced during subthreshold $\theta$ oscillation in CA3 neurons. Left, representative example. Presynaptic spikes are triggered at different phases during a subthreshold oscillation of the membrane potential at $4 \mathrm{~Hz}$. Note that facilitation is observed when the spike is triggered during the hyperpolarized phases of the oscillation. Right, quantitative data $(n=8)$. Stars: significant changes $(W i l c o x o n, P<0.05)$.

presynaptic neuron was found to enhance synaptic strength (109.6 $\pm 2.3 \%, n=13$, Wilcoxon test, $P<0.05$; Fig. $4 \mathrm{a})$.

To confirm that h-ADF in L5 pyramidal neurons was associated with axonal spike amplitude increase, simultaneous whole-cell recordings from the soma and cut-end axons (blebs) were obtained $(50-80 \mu \mathrm{m}$ from the soma) in L5 pyramidal neurons. Transient hyperpolarization of the soma (approximately $-13 \mathrm{mV}$ ) enhanced the amplitude of the spike overshoot in the axon but not in the soma $(+5.5 \pm 1.5$ versus $-0.3 \pm 1.1 \mathrm{mV}$, $n=5$, Mann-Whitney, $P<0.05$; Fig. 4b). The speed of depolarization was also augmented (from $251 \pm 59$ to $\left.289 \pm 56 \mathrm{mVms}^{-1}, \quad n=5\right)$ and the spike threshold was hyperpolarized (from $-35.7 \pm 5.2$ to $-38.8 \pm 4.3 \mathrm{mV}, n=5$ ). We conclude that h-ADF in both CA3 and L5 pyramidal cells is associated with the increase in the spike amplitude measured in the axon.

h-ADF is associated with enhanced axonal calcium signals. We next used $\mathrm{Ca}^{2+}$ imaging to determine the consequence of hyperpolarization-induced enhancement of spike amplitude in the axon. CA3 pyramidal neurons were filled with $50 \mu \mathrm{M}$ Alexa-594; $250 \mu \mathrm{M}$ Fluo-4 and spike-evoked calcium signals were measured in putative en passant boutons at distances ranging between 150 and $250 \mu \mathrm{m}$ from the soma (Fig. 5a). The integral of the spike-evoked $\mathrm{Ca}^{2+}$ transient was increased when the presynaptic spike was evoked following a transient hyperpolarization of $\sim 20 \mathrm{mV} \quad(126 \pm 10 \%, n=5$; Fig. 5b). We conclude that, during h-ADF, presynaptic hyperpolarization enhances both presynaptic spike amplitude and spike-induced $\mathrm{Ca}^{2+}$ influx, which subsequently enhances glutamate release.
Nav channel inactivation in the axon determines h-ADF. The increased amplitude of the axonal spike during hyperpolarization could be due to the recovery of Nav channels from inactivation. To confirm the role of sodium channel inactivation in h-ADF, we used a NEURON model of two monosynaptically connected CA3 neurons. We then determined the incidence of modifying inactivation of sodium channels in the axon on h-ADF. When the half-inactivation of axonal sodium channels was set to $-80 \mathrm{mV}$ (refs 18,19 ), somatic hyperpolarization enhanced the spike amplitude, the charge of spike-evoked calcium current and synaptic transmission (Fig. 6a, left). This is due to the recovery of Nav channels from inactivation by hyperpolarization (Fig. 6b, left). However, no change occurred if the halfinactivation of the axonal sodium channels was set to $-70 \mathrm{mV}$ (Fig. 6a, right). In this latter case, the proportion of available Nav channels is already very high at resting membrane potential, producing an AP of full amplitude (Fig. 6a,b, right). Therefore, the recovery from inactivation does not further affect the presynaptic spike amplitude. Thus, h-ADF in the model is due to the recovery of Nav channels from inactivation and is increased by hyperpolarizing Nav halfinactivation (Fig. 6c).

To test experimentally this last assumption, we measured $\mathrm{h}-\mathrm{ADF}$ in the presence of carbamazepine $(\mathrm{CBZ}, 100 \mu \mathrm{M})$, an antiepileptic drug that hyperpolarizes Nav half-inactivation by $6 \mathrm{mV}$ (ref. 23). CBZ reduced spike amplitude (90 $\pm 2 \%$ of control, $n=10$; Supplementary Fig. 3) and synaptic transmission (50 $\pm 6 \%$ of control, $n=10$; Supplementary Fig. 3 ). As expected, hyperpolarizing Nav inactivation by $\mathrm{CBZ}$ increased $\mathrm{h}-\mathrm{ADF}$ in mature CA3 neurons expressing no h-ADF (from $102.3 \%$ in control to $110.3 \%$ in the presence of CBZ, $n=10$, Wilcoxon $P<0.05$; Fig. 6d,e). 

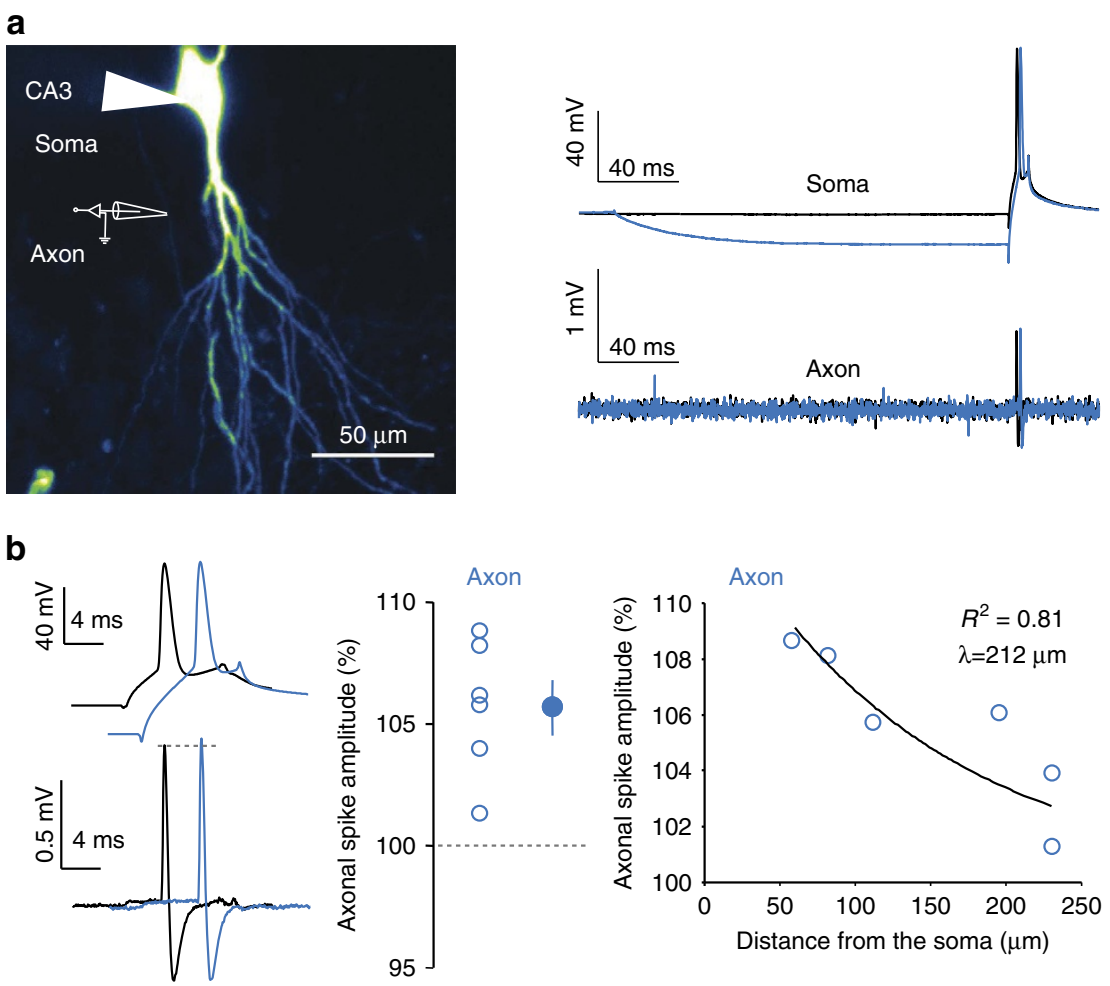

Figure 3 | h-ADF enhances spike amplitude in the axon. (a) Left, confocal image of a CA3 neuron filled with Alexa 488. The axon collateral (white arrow) is identified on the left and recorded in a cell-attached configuration. Right, simultaneous recordings from the soma (top) and axon (bottom) when the spike is triggered from resting membrane potential (black) or from a transient hyperpolarizing pre-pulse (blue). (b) Left, comparison of the spike amplitude measured in the axon evoked with (blue) or without (black) hyperpolarizing pre-pulse. Note the increase in amplitude in the axon when the spike is triggered from the hyperpolarizing pre-pulse. Middle, quantitative analysis of the hyperpolarization-induced enhancement of the axonal spike amplitude in six neurons. Right, scatter plot of the change in the axonal spike amplitude as a function of axonal distance (exponential fit, $y=11.6 e^{-x / 212}, r^{2}=0.81$ ).

Moreover, we used our NEURON model to simulate axonal Nav-channel availability during a theta oscillation similar to the one used in Fig. 2b. Nav channels were found to inactivate during depolarization and recover during hyperpolarization, explaining the EPSC modulation during the oscillation (Supplementary Fig. 4). However, inactivation is quicker than recovery during the oscillation because of the slower Nav kinetics at depolarized potentials (Supplementary Fig. 4). This explains why the EPSCs produced at $163 \mathrm{~ms}$ did not present any h-ADF, although the spike is emitted from a slightly hyperpolarized potential (Fig. 2b). In fact, at this point of the oscillation Nav channels did not have enough time to recover from inactivation (Supplementary Fig. 4).

Altogether, those results support the fact that $\mathrm{h}-\mathrm{ADF}$ is due to the recovery of Nav channels from inactivation.

Nav channel density determines the strength of h-ADF. h-ADF depends on the availability of sodium channels in the axon. Thus, reducing the density of Nav channels should affect h-ADF. In fact, our model showed that reducing Nav channel density to $70 \%$ of the control condition enhanced h-ADF from 130 to $180 \%$ (Fig. 7a). The critical parameter here was the gain of presynaptic spike overshoot that depends on activatable $\mathrm{Na}$ conductance (Fig. 7b). Under control condition, this value was already high, and hyperpolarizing the presynaptic element from -78 to $-93 \mathrm{mV}$ enhanced the amplitude of the spike by $28 \%$. When the density of Nav was reduced, the same hyperpolarization enhanced the amplitude of the presynaptic AP by $42 \%$.

We next verified experimentally that reducing Nav channel density increased $\mathrm{h}$-ADF in CA3 neurons. We therefore partially blocked Nav channels with a low concentration of tetrodotoxin (TTX) applied in the bath $(15-25 \mathrm{nM})$. At this concentration TTX blocks $\sim 80 \%$ of the $\mathrm{Na}^{+}$current but preserves induction of fast $\mathrm{Na}^{+}$spikes ${ }^{24,25}$. In the presence of TTX, the spike amplitude in the soma was reduced by $45 \pm 4 \%$ $(n=9)$ and synaptic transmission at CA3-CA3 connections was reduced by $55 \pm 8 \% \quad(n=9$; Supplementary Fig. 5). Most importantly, reducing the proportion of activatable Nav channels with $15-25 \mathrm{nM}$ TTX was found to greatly enhance $\mathrm{h}-\mathrm{ADF}$ in mature neurons expressing no h-ADF (from $103 \pm 3 \%$ in control to $121 \pm 4 \%$ in the presence of TTX, $n=6$, Wilcoxon $P<0.05$; Fig. $7 \mathrm{c}, \mathrm{d})$. These data therefore confirm that h-ADF in CA3 neurons depends on the availability of Nav channels.

T-type $\mathrm{Ca}^{2+}$ channels are present in the axon. They could be activated during the hyperpolarization-depolarization sequence used to induce h-ADF and thus may account for h-ADF. However, h-ADF was found to remain stable in the presence of $100 \mathrm{nM}$ mibefradil, a T-type channel blocker (from 112.2 $\pm 1.1 \%$ in control to $116.2 \pm 11.9 \%$ with mibefradil, $n=3$; data not shown), suggesting that $\mathrm{T}$-type $\mathrm{Ca}^{2}+$ channels do not participate in $\mathrm{h}-\mathrm{ADF}$.

h-ADF promotes network synchrony. We next tested the implication of h-ADF in network synchrony using a hippocampal network model formed by 80 pyramidal-like excitatory cells (e-cells) and 20 interneuron-like inhibitory cells (i-cells) interconnected (Fig. 8a; see Methods). e- and i-cells were fed by stochastic input. The network of e-cells became synchronized, and oscillations in the gamma range appeared as synaptic strength between e-cells increased (Supplementary Fig. 6). These oscillations were driven by i-cells: activation of e-cells was found 
a
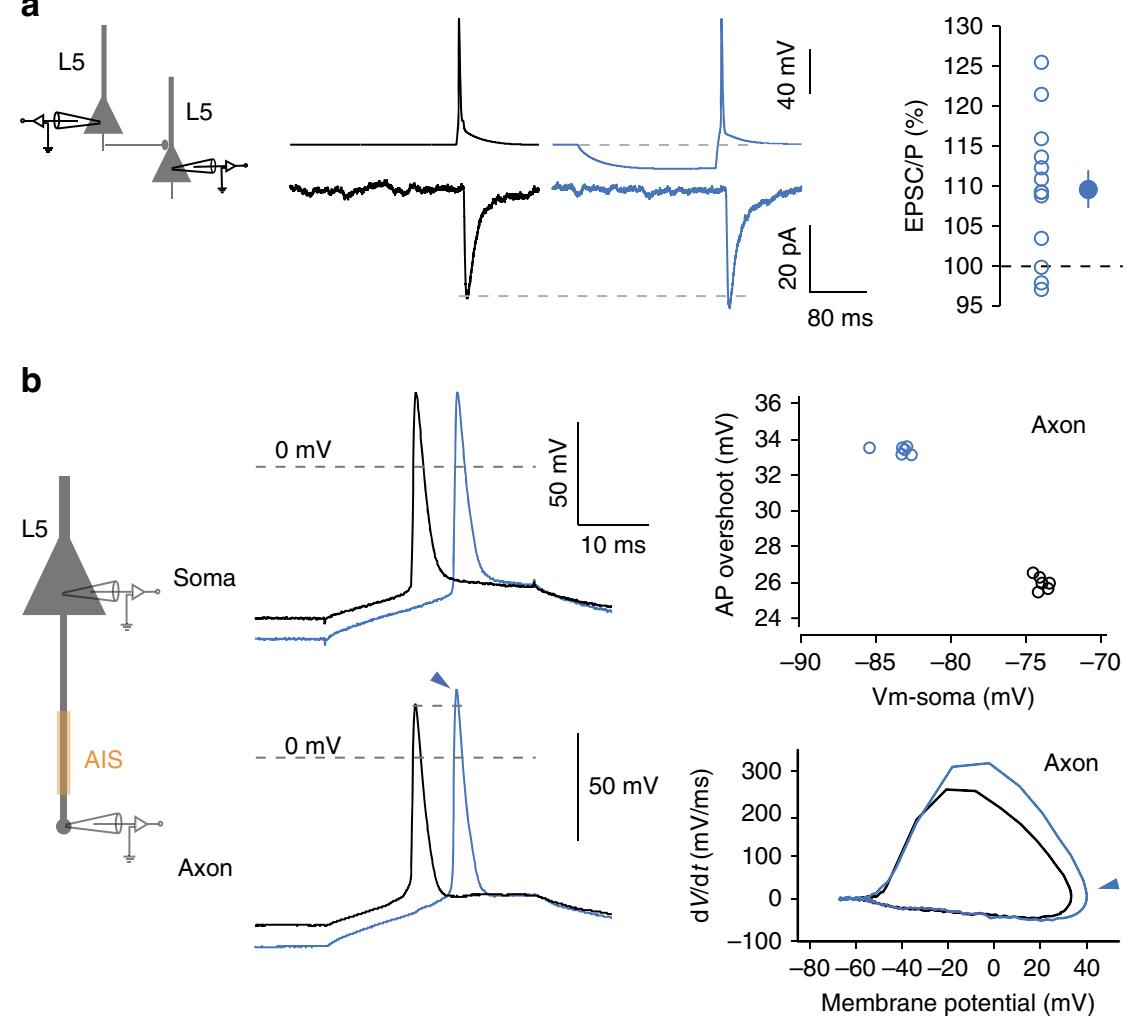

Figure 4 | h-ADF at L5-L5 synapses. (a) Paired recording of synaptically connected L5 pyramidal neurons. Middle, synaptic facilitation produced by a brief presynaptic hyperpolarization ( $-20 \mathrm{mV} ; 200 \mathrm{~ms}$ ). The EPSCs correspond to averages over 25 traces. Right, h-ADF obtained in 12 L5-L5 pairs. (b) Dual soma-axon recordings in L5 pyramidal neurons. Left, experimental design showing double recording from the soma and the axonal bleb of $L 5$ pyramidal neuron. Middle, Soma-axon recording in L5 pyramidal neurons. Note that a brief hyperpolarization of the soma enhances the amplitude of the spike in the axon but not in the soma. Right top, AP overshoot measured in the axon as a function of membrane potential in the cell body, for resting (black) or hyperpolarized (blue) potentials ( $n=6$ traces for each case). Right bottom, phase plot of the axonal spikes evoked at rest (black) and following a brief hyperpolarization (blue). Note the enhanced amplitude after a brief hyperpolarization (arrow). The rate of depolarization is also enhanced and the spike threshold is slightly hyperpolarized.

a

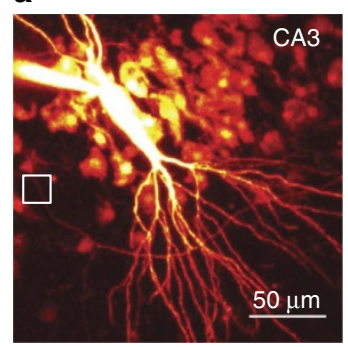

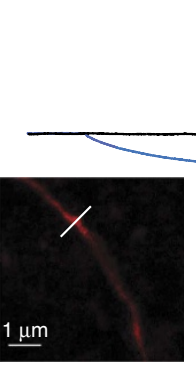

b

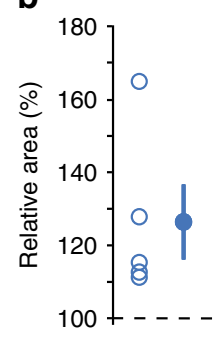

Figure 5 | h-ADF enhances spike-evoked calcium signal in the presynaptic terminal of CA3 neurons. (a) A brief hyperpolarizing pre-pulse enhances the spike-evoked $\mathrm{Ca}^{2+}$ transient. Left top, experimental design showing a CA3 pyramidal neuron filled with Alexa-594 and Fluo-4. White box: area enlarged at right, showing a presynaptic bouton. Right top, voltage traces recorded in the cell body of a CA3 pyramidal neuron. Right bottom, example of fluorescent signals recorded in the presynaptic bouton. The spike-evoked $\mathrm{Ca}^{2}+$ transient was increased by $\sim 20 \%$ when the presynaptic spike was evoked following a transient hyperpolarization. (b) Quantitative data $(n=5)$.

to promote the activation of i-cells, which in turn silenced the whole network (Supplementary Fig. 6). Since h-ADF increases interpyramidal synaptic strength when the presynaptic spike is preceded by an IPSP, h-ADF is a good candidate to promote these i-cell-driven oscillations.

The h-ADF rule was incorporated in the network by increasing synaptic strength between e-cells according to the membrane potential measured $17 \mathrm{~ms}$ before the spike. In fact, synaptic strength was increased by $20 \%$ if the presynaptic potential was below $-84 \mathrm{mV}$ (Fig. 8b). This rule was directly derived from values measured experimentally (see Figs 1a and 2a). For an e-cellsynaptic strength of $2.8 \mathrm{mS}$, adding h-ADF in the network markedly enhanced both the firing frequency and synchrony across e-cells (Fig. 8c-e). In fact, the propensity to oscillate in the gamma range was greatly facilitated if h-ADF between e-cells was effective (Fig. 8e). Interestingly, in a network with shunting 
a
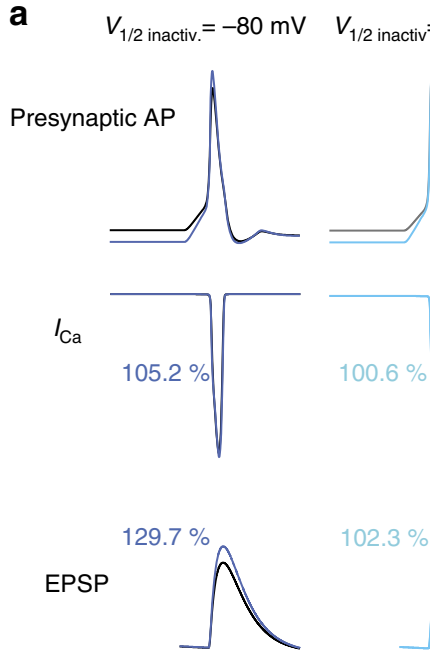

$-70 \mathrm{mV}$
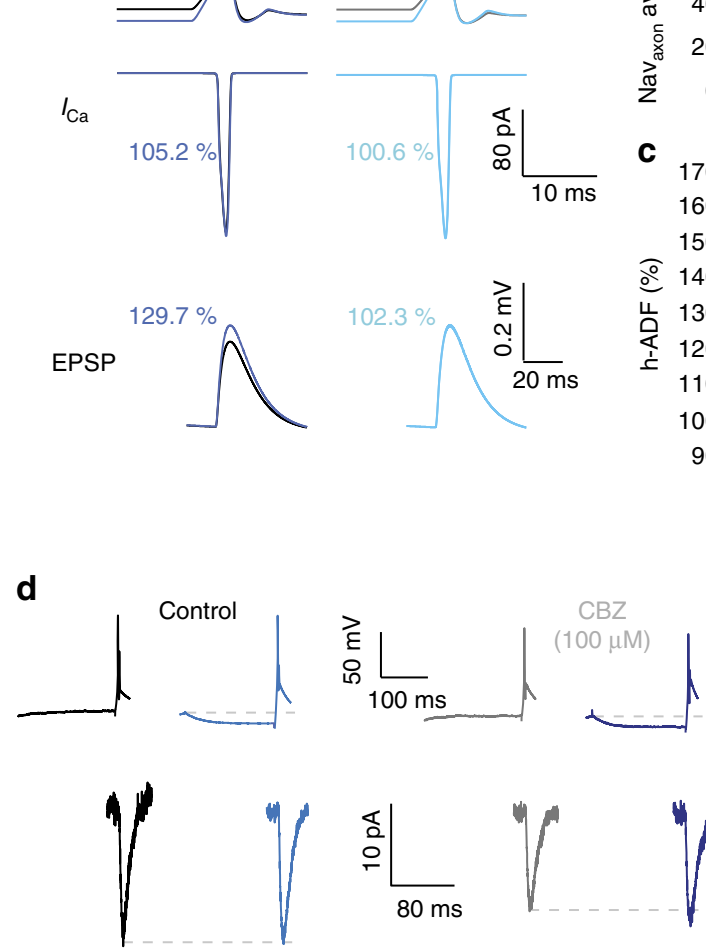

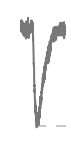

b
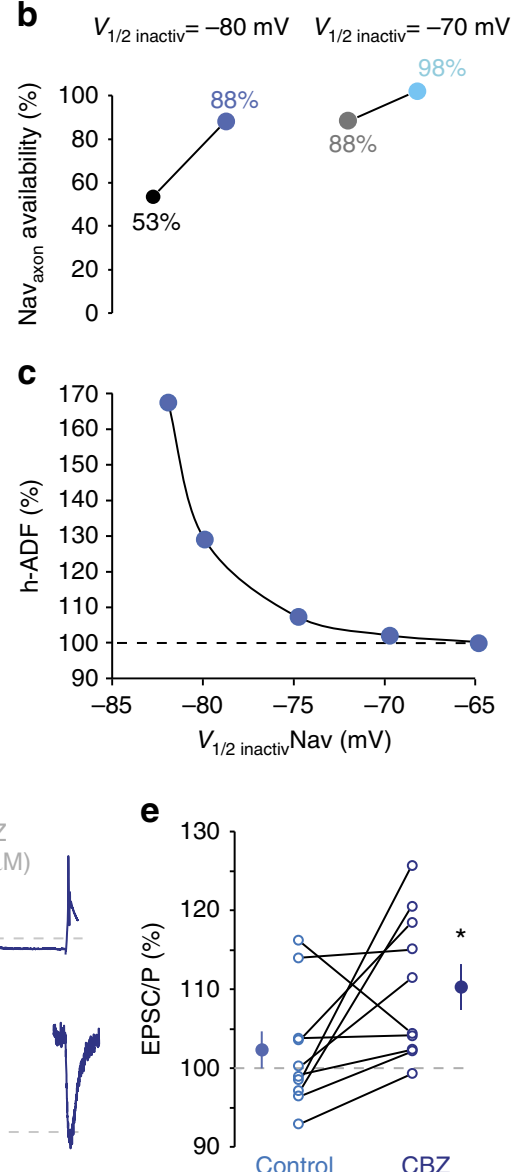

Figure 6 | Role of Nav inactivation in h-ADF. (a) Simulated h-ADF in control conditions ( $V_{1 / 2}$ inactivation $=-80 \mathrm{mV}$ for axonal sodium channels). Note the increased amplitude of the spike. Lack of $h-A D F$ when the half-inactivation of the axonal sodium channel is depolarized $\left(V_{1 / 2}=-70 \mathrm{mV}\right)$. (b) Summary of the availability of $\mathrm{Nav}_{\text {axon }}$ with $V_{1 / 2}$ inactivation $=-80 \mathrm{mV}$ or $-70 \mathrm{mV}$. Note the marked increase with -80 but not $-70 \mathrm{mV}$. (c) Magnitude of simulated h-ADF as a function of $V_{1 / 2}$ inactivation of Nav channels in the axon. Note the increase in h-ADF induced by the hyperpolarization of $V_{1 / 2}$. (d) Experimental enhancement of Nav inactivation with CBZ increases the magnitude of h-ADF. Under control condition (left), this connection expresses no h-ADF. When CBZ is added, h-ADF is now visible (right). (e) Quantitative data for 10 mature CA3-CA3 connections (DIV 24-32). Star: Wilcoxon, $P<0.05$.

inhibition $\left(E_{\mathrm{Cl}}=-73 \mathrm{mV}\right.$ instead of $-80 \mathrm{mV}$ in control condition), h-ADF rule did not improve synchrony and did not promote gamma oscillations (Supplementary Fig. 6). However, as $\mathrm{h}$-ADF increases the synaptic strength between e-cells, its synchronizing effect could be simply due to the increase in the spike rate of the network. To increase the spike rate without affecting synaptic strength, we decided to fix the inter-e-cell strength at $2.5 \mathrm{mS}$ and increase the external drive frequency of e-cells from 6 to $20 \mathrm{~Hz}$. We plotted the coefficient of synchronization versus the spike rate of the network. Even if synchrony showed to be linearly correlated to spike rate, h-ADF increased the coefficient of synchronization for any given spike rate in the 4-14-Hz range (Supplementary Fig. 6). This showed that for low spike rate, h-ADF increases synchrony independently of the mean network activity. In conclusion, in our model, h-ADF increases network synchronization and promotes oscillations by linking interpyramidal synaptic strength with activity of interneurons.

\section{Discussion}

We report here a physiologically relevant mode of $\mathrm{AD}$ regulation of synaptic transmission at CA3-CA3 and L5-L5 connections. Synaptic transmission was found to be enhanced by 20\% owing to brief physiological hyperpolarization (15-200 ms) preceding the presynaptic AP. $\mathrm{h}-\mathrm{ADF}$ is associated with a gain in AP amplitude measured in the axon, and is modulated by pharmacological agents targeting Nav channels. Thus, h-ADF can be considered as a novel form of activity-dependent synaptic plasticity that depends on $\mathrm{Nav}$ channels. Although h-ADF was found to be developmentally downregulated, mature CA3 neurons still expressed robust h-ADF (16\%) in physiological calcium $(1.3 \mathrm{mM})$. h-ADF is mediated by an increase in presynaptic glutamate release. It can be induced by IPSP-like synaptic conductance or theta-like oscillations. Integrated in a network model, h-ADF promotes network synchrony and favours the emergence of gamma oscillations.

$\mathrm{h}-\mathrm{ADF}$ is an unanticipated mode of $\mathrm{AD}$ facilitation of excitatory synaptic transmission, induced by a brief hyperpolarization of the presynaptic cell. While analogue modulation of spike-evoked synaptic transmission had been reported to occur in many neuronal types following presynaptic depolarization ${ }^{1,5,6,8,10,12,13}$, it was not entirely clear whether presynaptic hyperpolarization robustly induced synaptic facilitation ${ }^{26-28}$. In these latter studies the underlying mechanisms were not identified. We characterize here for the first time the induction of h-ADF in CA3 and L5 pyramidal neurons. This facilitation was found to fully develop with moderate hyperpolarization. In fact, a $10-\mathrm{mV}$ hyperpolarization from resting membrane potential was found to be sufficient to enhance synaptic transmission by 20\% at CA3CA3 synapses, indicating that the facilitation factor was $\sim 2 \%$ per $\mathrm{mV}$ of hyperpolarization. Interestingly, facilitation was not further 
a

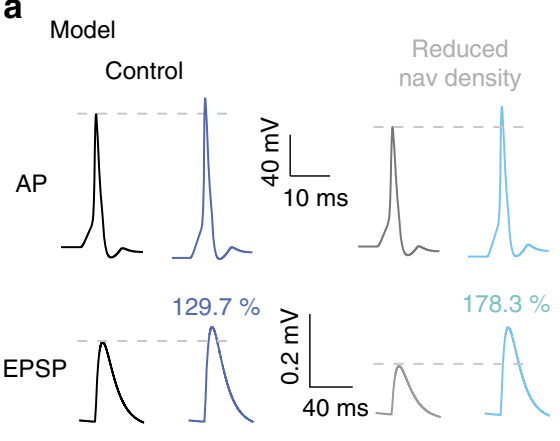

b
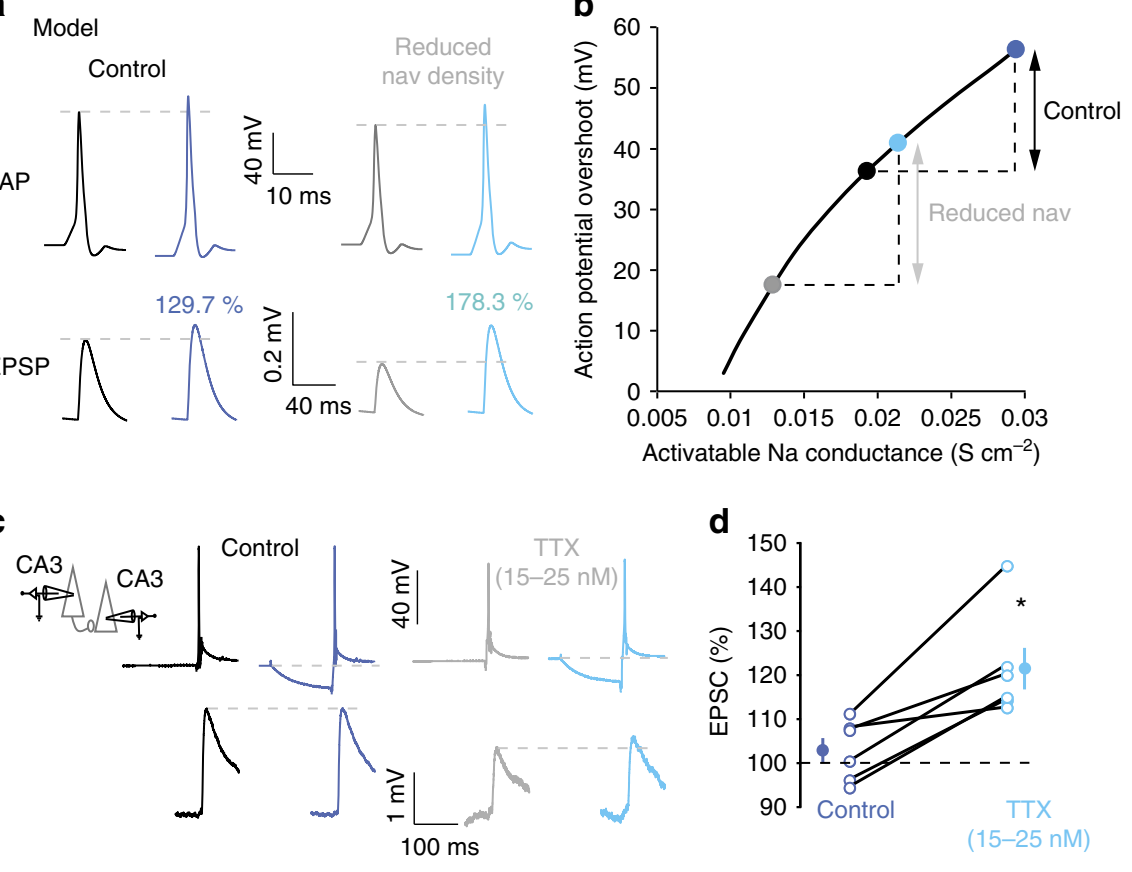

d

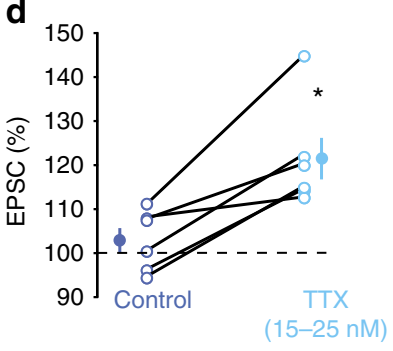

Figure 7 | Decreasing Nav channel density with TTX enhances h-ADF. (a) Reduction of Nav channel density in the model of h-ADF. Under control conditions (left), h-ADF amounts to $+30 \%$. After reducing the Nav channel density ( $70 \%$ of the control, right), h-ADF is increased to $+80 \%$. (b) Modulation of the presynaptic spike amplitude as a function of activatable Na conductance. Under control conditions, the hyperpolarization from - 78 to $-93 \mathrm{mV}$ only slightly increases the spike amplitude (black double arrow). When the Nav channel density is reduced, the increase in the spike amplitude is enhanced by $20 \%$ (light-blue double arrow). (c) Experimental reduction of Nav density with TTX. Under control condition (left), this connection expresses no h-ADF. When a low concentration of TTX is added, transmission is preserved and h-ADF is now visible (right). (d) Quantitative data for six mature CA3-CA3 connections (DIV 20-32). Star: Wilcoxon, $P<0.05$.

enhanced by a larger hyperpolarization, suggesting that the presynaptic $\mathrm{Na}^{+}$spike reaches its maximal amplitude with a small fraction of available Nav channels ${ }^{24}$. In addition, simulated IPSPs preceding the spike by $50 \mathrm{~ms}$ enhanced synaptic transmission in a graded manner.

We show that h-ADF and d-ADF are coexpressed at CA3-CA3 pyramidal cell synapses. A combination of stimuli that separately induced $\mathrm{d}-\mathrm{ADF}$ and $\mathrm{h}-\mathrm{ADF}$ produced facilitation that was significantly greater, indicating that the two processes are mechanistically distinct. In fact, d-ADF depends on Kv1.1 and h-ADF depends on Nav channels. In contrast to d-ADF that requires several seconds to be fully expressed ${ }^{5,6,13}$, h-ADF can be induced by fast $(\sim 15 \mathrm{~ms})$ hyperpolarization of the presynaptic neuron. Thus, h-ADF is better suited than $\mathrm{d}-\mathrm{ADF}$ for fast dynamics of network activity.

$\mathrm{h}-\mathrm{ADF}$ is observed at both hippocampal CA3 cells and L5 pyramidal neurons, indicating that it might be a general process in local synaptic circuits. h-ADF seems to be developmentally regulated in hippocampal CA3 cells and declines from young CA3 neurons to mature neurons. The developmental modulation may result from the increase in the density of voltage-gated sodium channels in the axon ${ }^{29-32}$. However, under physiological conditions ( $1.3 \mathrm{mM}$ external $\left.\mathrm{Ca}^{2+}\right)$, h-ADF measured at mature CA3-CA3 synapses is robust and amounts to $16 \%$.

Two mechanisms of analogue modulation of spike-evoked synaptic transmission have been identified so far. Release can be elevated by voltage inactivation of Kv1 channels, making the presynaptic spike broader ${ }^{5,6,13}$ or by voltage activation of $\mathrm{P} / \mathrm{Q}$-type $\mathrm{Ca}^{2+}$ channels that elevate basal calcium ${ }^{8,9}$. While the underlying mechanisms are different, these forms of ADF share common characteristics: they are depolarization-driven and need a long depolarization (hundreds of milliseconds to few seconds) to be fully expressed. Here we show that ADF can also be induced by presynaptic hyperpolarization. This hyperpolarization propagates passively along the axon to allow the recovery of Nav channel from inactivation. In turn, it increases AP amplitude, thus enhancing $\mathrm{Ca}^{2+}$ entry in the presynaptic bouton and subsequently elevating glutamate release. All these steps have been dissected here with the use of electrophysiological, pharmacological, imaging and computational approaches.

The major consequence of presynaptic hyperpolarization is the enhancement of spike amplitude in the axon. This enhancement was reported in both CA3 and L5 neurons using cell-attached or whole-cell recordings, respectively. It is supposed to result from the fast recovery of $\mathrm{Nav}$ channels from inactivation. Although $\mathrm{Na}^{+}$channel inactivation has not been directly measured in our study, we assume that, at resting membrane potential, a very large proportion of $\mathrm{Na}^{+}$channels are inactivated in the axon of CA3 pyramidal cells, as in neocortical pyramidal neurons and hippocampal granule cells ${ }^{18,19,33}$. As predicted by cable theory, the modulation in extracellular spike amplitude was found to decline with the axonal distance. The space constant here has been estimated to be $\sim 212 \mu \mathrm{m}$. Compared with d-ADF, this space constant is slightly shorter probably because of the frequency dependence of the space constant along axons ${ }^{5,34}$. However, h-ADF could affect more distal synapses in CA1 or L5 pyramidal neurons that express long axonal space constant $(700-1,000 \mu \mathrm{m})^{34,35}$.

The involvement of Nav channels was shown by modulating their availability. The model predicted that decreasing the density of Nav channels would increase the hyperpolarization-induced modulation of the presynaptic AP amplitude and it would subsequently increase h-ADF. Experimentally, low concentrations of TTX (15-25 nM) increased h-ADF by a factor 5 (Fig. 7). In 
a

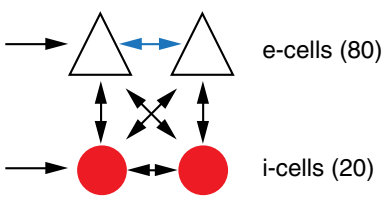

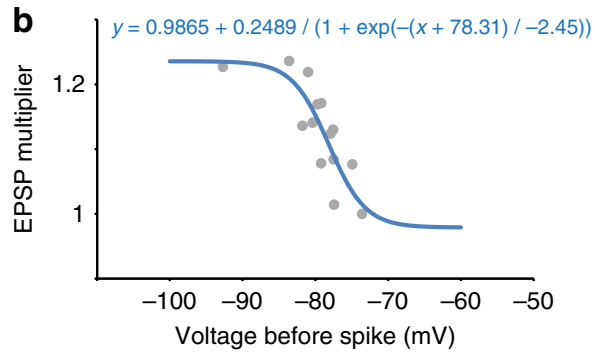

C

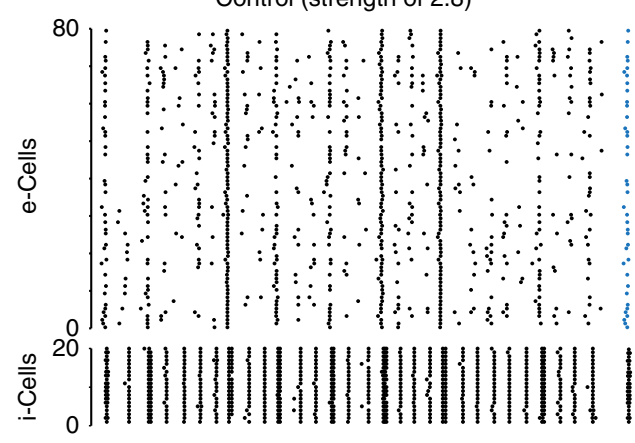

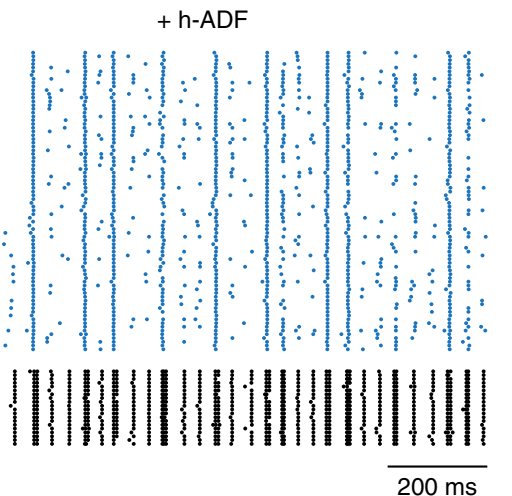

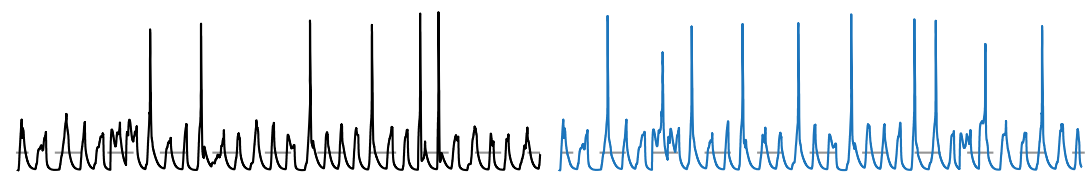

$40 \mathrm{mV}$

d

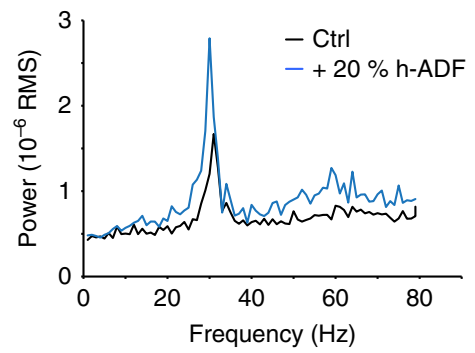

e

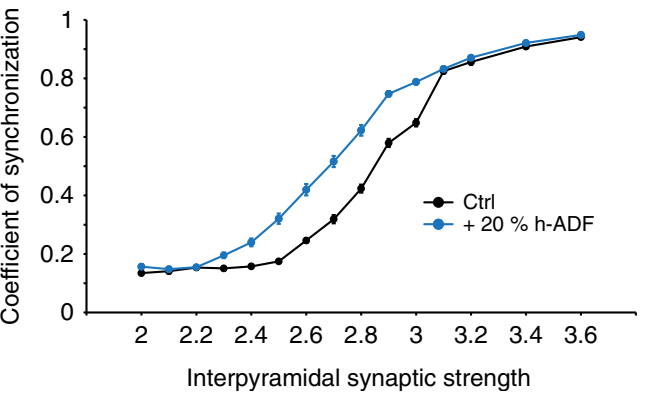

Figure 8 | h-ADF promotes network synchrony. (a) Scheme of a CA3 network model. The network is composed of 80 e-cells (white triangles) and 20 $\mathrm{i}$-cells (red circles). Pyramidal cells and interneurons were fed by stochastic input. The connections between pyramidal neurons (blue arrows) are the only connections in which h-ADF can be added as h-ADF was not tested experimentally in other connections. (b) h-ADF rule at excitatory synapses between pyramidal neurons. A maximal 20\% facilitation is applied, according to the membrane voltage measured 17 ms before the spike. (c) Effect of the h-ADF rule on network synchrony. Left top, rastergram showing the network activity in control conditions with a synaptic strength of $2.8 \mathrm{mS}$. Left bottom, representative trace in an e-cell. Right top, with the h-ADF rule ( $+20 \% \mathrm{~h}-\mathrm{ADF})$, the synchrony is increased. Right bottom, representative trace in an e-cell. Note that membrane potential crosses the $-73-\mathrm{mV}$ limit between spikes (dotted lines). (d) Power spectrum of the data shown in c (synaptic strength of $2.8 \mathrm{mS}$ ). Adding h-ADF rules dramatically increases the network synchrony around the gamma frequency $(29 \mathrm{~Hz})$. (e) Synchronization coefficients calculated for synaptic strengths from 2 to 3.6. Incorporation of h-ADF increases synchrony (blue).

addition, our model showed that hyperpolarizing the halfinactivation of Nav channel in the axon enhanced the hyperpolarization-induced modulation of the spike amplitude and subsequently increased h-ADF. Further supporting the contribution of Nav channel in h-ADF, we show that hyperpolarizing the inactivation properties of sodium channels with CBZ also increased h-ADF.

The Nav channel-dependent enhancement of spike amplitude induced by hyperpolarization caused an elevation in presynaptic calcium. In fact, a brief hyperpolarization before the AP increased the evoked calcium signal measured in putative presynaptic boutons. A hyperpolarization indeed increased AP amplitude, leading to a larger calcium influx in the bouton and thus a bigger postsynaptic response. These results were reproduced in our model and are consistent with previous studies ${ }^{36,37}$.

Presynaptic transient hyperpolarization has a major consequence on fast activating or inactivating currents. Except the recovery of Nav channels from inactivation, the biophysical state of Cav channels might, in principle, be also altered. h-ADF is not suppressed by mibefradil, a selective blocker of T-type 
$\mathrm{Ca}^{2}+$ channels. In addition, h-ADF does not result from the increase in driving force for $\mathrm{Ca}^{2}+$ because the hyperpolarization occurs before and not during the presynaptic AP.

A major functional consequence of h-ADF reported in our study is the optimization of synaptic excitation in local circuits by IPSPs preceding presynaptic APs. Thus, our results strongly suggest that synaptic transmission between pyramidal cells that fire in rebound on activation of basket cells could be facilitated ${ }^{38}$, subsequently enhancing the coherence of network oscillations. The importance of h-ADF in brain function is supported by several lines of evidence. First, biologically realistic hyperpolarization such as $\mathrm{GABA}_{\mathrm{A}}$-like IPSPs simulated using the dynamic-clamp induced robust h-ADF. In this case, the hyperpolarization was small $(2-10 \mathrm{mV})$ and the delay between the IPSP and the spike was in the physiological range $(50 \mathrm{~ms})$. Similarly, presynaptic oscillation of the membrane potential was found to induce h-ADF when the spike was triggered during the hyperpolarized part of the oscillation. In this case, h-ADF can be seen as a normalizing effect: during the depolarizing phase of the oscillation, the probability to trigger a spike is high and the postsynaptic response is low, whereas during the hyperpolarizing phase of the oscillation the spike probability is low and the response is high. We performed our experiments for a $4-\mathrm{Hz}$ oscillation; however, given the quick kinetics of h-ADF (a 15-ms hyperpolarization is enough to fully induce it), it should be observed for higher theta rhythms $(8-12 \mathrm{~Hz})$.

A particular important result of our study is the effect of h-ADF on a model of network activity. In fact, h-ADF improved network synchrony and promoted gamma oscillation in a simple interneuron-like-driven network model. Incorporated at synapses established between pyramidal-like cells, h-ADF increased the global synchrony of the network and promoted the emergence of gamma oscillation. It is important to notice that h-ADF also acts as a mechanism optimizing biological energy. A given synchrony is obtained with less excitatory synaptic strength. The specificity of the effect was demonstrated by making inhibitory synapses shunting instead of hyperpolarizing. In this case, the presence of h-ADF had no effect. These results strongly suggest that Nav channel modulation of synaptic efficacy is probably a major mechanism for modulating information processing in local neural circuits.

\section{Methods}

Organotypic cultures of the rat hippocampus. Organotypic cultures of the rat hippocampus were prepared ${ }^{21}$, according to the European and Institutional guidelines (Council Directive 86/609/EEC and French National Research Council and approved by the local health authority (\# D 13055 08, Préfecture des Bouchesdu-Rhône, Marseille)). Postnatal day 5-7 Wistar rats of both sexes were anaesthetized with chloral hydrate injection, the brain was rapidly extracted from the skull and each hippocampus was isolated. Hippocampal slices $(350 \mu \mathrm{m})$ were maintained for up to $30-35$ days in an incubator at $34^{\circ} \mathrm{C}, 95 \% \mathrm{O}_{2}-5 \% \mathrm{CO}_{2}$. The culture medium contained (in ml) $25 \mathrm{MEM}, 12.5 \mathrm{HBSS}, 12.5$ horse serum, 0.5 penicillin $\left(10,000 \mathrm{U} \mathrm{ml}^{-1}\right), 0.5$ streptomycin $\left(10,000 \mu \mathrm{g} \mathrm{ml}^{-1}\right), 0.8$ glucose $(1 \mathrm{M})$, 0.1 ascorbic acid $\left(1 \mathrm{mg} \mathrm{ml}^{-1}\right), 0.4$ HEPES $(1 \mathrm{M}), 0.5 \mathrm{~B} 27$ and 8.95 sterile $\mathrm{H}_{2} \mathrm{O}$. To avoid glial proliferation, $5 \mu \mathrm{M}$ Ara-C was added to the medium starting at 3 DIV. Pyramidal cells from CA3 area were recorded at the age of 8-12 DIV or 24-32 DIV when mentioned.

Acute slices of the rat neocortex. Neocortical slices $(350-400 \mu \mathrm{m})$ were obtained from 14- to 20-day-old Wistar rats of both sexes. Rats were deeply anaesthetized with chloral hydrate (intraperitoneal, $200 \mathrm{mg} \mathrm{kg}^{-1}$ ) and killed by decapitation. Slices were cut in an ice-cold solution containing (mM): 280 sucrose, $26 \mathrm{NaHCO}_{3}$, $10 \mathrm{D}$-glucose, $10 \mathrm{MgCl}_{2}, 1.3 \mathrm{KCl}$ and $1 \mathrm{CaCl}_{2}$, and were bubbled with $95 \% \mathrm{O}_{2}-5 \%$ $\mathrm{CO}_{2}, \mathrm{pH}$ 7.4. Slices were recovered $(1 \mathrm{~h})$ in a solution containing $(\mathrm{mM}): 125 \mathrm{NaCl}$, $26 \mathrm{NaHCO}_{3}, 2 \mathrm{CaCl}_{2}, 2.5 \mathrm{KCl}, 2 \mathrm{MgCl}_{2}, 0.8 \mathrm{NaH}_{2} \mathrm{PO}_{4}$ and $10 \mathrm{D}$-glucose, and were equilibrated with $95 \% \mathrm{O}_{2}-5 \% \mathrm{CO}_{2}$. Each slice was transferred to a submerged chamber mounted on an upright microscope (Olympus BX51WI or Zeiss LSM710 ), and neurons were visualized using differential interference contrast infrared videomicroscopy.
Paired recordings and analysis. Dual recordings from pairs of neurons were obtained as previously described ${ }^{21,39}$. The external saline contained (in mM): 125 $\mathrm{NaCl}, 26 \mathrm{NaHCO}_{3}, 3 \mathrm{CaCl}_{2}$ (1.3 for physiological calcium solution), $2.5 \mathrm{KCl}$, $2 \mathrm{MgCl}_{2}$ (1 for physiological calcium solution), $0.8 \mathrm{NaH}_{2} \mathrm{PO}_{4}$ and $10 \mathrm{D}$-glucose, and was equilibrated with $95 \% \mathrm{O}_{2}-5 \% \mathrm{CO}_{2}$. Patch pipettes (5-10 M $\Omega$ ) were pulled from borosilicate glass and filled with an intracellular solution containing $(\mathrm{mM})$ : $120 \mathrm{~K}$ gluconate, $20 \mathrm{KCl}, 10 \mathrm{HEPES}, 0.5$ EGTA, $2 \mathrm{MgCl}_{2}, 2 \mathrm{Na}_{2} \mathrm{ATP}$ and 0.3 NaGTP (pH 7.4). Recordings were performed at $30^{\circ} \mathrm{C}$ in a temperature-controlled recording chamber (Luigs \& Neumann, Ratingen, Germany). Usually, the presynaptic neuron was recorded in current clamp and the postsynaptic cell in voltage clamp. Both pre- and postsynaptic cells were held at their resting membrane potential (approximately $-77 \mathrm{mV}$ ). Presynaptic APs were generated by injecting brief $(5 \mathrm{~ms})$ depolarizing pulses of current at a frequency of $0.1 \mathrm{~Hz}$. PPR was assessed with two presynaptic stimulations (50-ms interval). Voltage and current signals were low-pass-filtered $(3 \mathrm{kHz})$, and sequences $(200-500 \mathrm{~ms})$ were acquired at $10-20 \mathrm{kHz}$ with pClamp (Axon Instruments, Molecular Devices) version 10. Electrophysiological signals were analysed with ClampFit (Axon Instruments) and custom-made softwares written in LabView (National Instruments). Postsynaptic responses could be averaged following alignment of the presynaptic APs using automatic peak detection. The presence or absence of a synaptic connection was determined on the basis of averages of 30-50 individual traces. TTX (Latoxan, $15-25 \mathrm{nM}$ ) was bath-applied. The membrane potential was corrected for the liquid junction potential $(-13 \mathrm{mV})$. Pooled data are represented as mean \pm s.e. in all the figures, and we used the Mann-Whitney $U$-test or Wilcoxon rank-signed test for statistical comparison.

Calcium imaging. CA3 pyramidal neurons were imaged using a LSM710 Zeiss confocal system. For imaging calcium in CA3 neurons, $50 \mu \mathrm{M}$ Alexa-594 and $250 \mu \mathrm{M}$ Fluo-4 (Invitrogen) were added to the pipette solution. Alexa-594 fluorescence was used to reveal neuronal morphology, whereas fluorescence signals emitted by Fluo- 4 were used for calcium imaging.

Laser sources for fluorescence excitation were set at $488 \mathrm{~nm}$ for Fluo- 4 and $543 \mathrm{~nm}$ for Alexa-594. Emitted fluorescence was collected between 500 and $580 \mathrm{~nm}$ for Fluo-4, and between 620 and $750 \mathrm{~nm}$ for Alexa-594. After whole-cell access, the dyes diffused at least 15-20 min before measuring fluorescence. APs were induced by short $(5-10 \mathrm{~ms})$ pulses of depolarizing current pulses $(900-1,400 \mathrm{pA})$ in the current clamp mode and were synchronized with calcium imaging in the line-scan mode. Depending on experiments, line-scan speed was set to $0.5-2 \mathrm{kHz}$.

Acquired Fluo- 4 fluorescence signals were converted to $\Delta F / F$ values. Peak amplitude and decay time of $\mathrm{Ca}^{2+}$ signals were calculated with a custom-made analysis programme written in LabView (National Instruments).

The axon was identified visually as a long, thin, aspiny process with constant diameter, emerging from the soma or from a primary dendrite near the cell body. The axon was followed until the first bulges of the membrane, revealing presynaptic boutons, were encountered.

Axonal recordings. Two modes of axonal recordings were used in this study. First, simultaneous recordings from the soma in whole-cell configuration and the axon in cell-attached configuration were obtained from CA3 pyramidal neurons as previously described ${ }^{25}$. The axon was recorded for 10-15 min after whole-cell access of the somatic compartment and the full labelling of the axon by Alexa 488 and visualized with the LSM-710 confocal microscope. To obtain cell-attached recording, a brief suction was applied to the pipette. Under these conditions, the spike measured in the axon had a positive polarity (amplitude $0.3-1.2 \mathrm{mV}$ ).

The second type of axonal recording was obtained in the whole-cell configuration. Simultaneous recordings from the soma and axonal cut ends (blebs, at $50-80 \mu \mathrm{m}$ from the cell body) were obtained in L5 pyramidal neurons. In that case, identification of the axonal bleb was made visually at the surface of the acute slice.

Dynamic clamp. Synaptic-ADF experiments (Fig. 2a) were performed using a dynamic-clamp system (SM-1; Cambridge Conductance, Cambridge, UK) and a computer-generated conductance profile delivered via $\mathrm{AD}$ interface (Digidata 1440A; Molecular Devices). The conductance profile was based on recordings of GABAergic currents obtained from CA3 neurons in voltage clamp while stimulating extracellularly the pyramidal layer in the presence of $2 \mathrm{mM}$ kynurenate (Sigma). The conductance waveform follows a double exponential profile:

$y=-\left(1-\exp \left(-\left(t / t_{\mathrm{r}}\right)\right)\right) \times \exp \left(-\left(t / t_{\mathrm{d}}\right)\right)$, where $t_{\mathrm{r}}=4.2 \mathrm{~ms}$ and $t_{\mathrm{d}}=14.5 \mathrm{~ms}$ (determined experimentally). The reversal potential for the GABAergic-like current was set at $-86 \mathrm{mV}$ for this specific experiment.

Modelling. A multicompartment model of a CA3 pyramidal neuron was simulated with NEURON 7.2. The diameter and length of each compartment are provided in Supplementary Table 1 . The passive electrical properties $C_{\mathrm{m}}$ and $R_{\mathrm{i}}$ were set to $1 \mu \mathrm{F} \mathrm{cm}^{-2}$ and $100 \Omega \mathrm{cm}$, respectively, uniformly throughout all compartments ${ }^{40}$ All simulations were run with $10-\mu$ s time steps and the nominal temperature of simulations was $28^{\circ} \mathrm{C}$. The voltage dependence of activation and inactivation of a Hodgkin-Huxley-based conductance models $\left(g_{\mathrm{NaSoma}}, g_{\mathrm{NaAxon}}, g_{\mathrm{KDR}}, g_{\mathrm{Kv} 1}\right.$ and $\left.g_{\mathrm{Ca}}\right)$ 
are given as follows:

$$
\begin{aligned}
g_{\mathrm{NaSoma}} & =G_{\mathrm{NaSoma}} \times m_{\text {Soma }} \times h_{\text {Soma }} \\
g_{\mathrm{NaAxon}} & =G_{\mathrm{NaAxon}} \times m_{\mathrm{Axon}} \times h_{\mathrm{Axon}} \\
g_{\mathrm{KDR}} & =G_{\mathrm{KDR}} \times n \\
g_{\mathrm{Kv} 1} & =G_{\mathrm{Kv} 1} \times p \times k \\
g_{\mathrm{CaP} / \mathrm{Q}} & =G_{\mathrm{CaP} / \mathrm{Q}} \times r
\end{aligned}
$$

where $m_{\text {Soma }}, m_{\text {Axon }}, n, p$ and $r$ are dynamic activation variables and $h_{\text {Soma }}, h_{\text {Axon }}$ and $k$ are dynamic inactivation variables. They evolve according to the following differential equations (adapted from ref. 19 for $\mathrm{Nav}_{S o m a}$ and $\mathrm{Nav}_{\mathrm{Axon}}$; ref. 41 for $\mathrm{K}_{\mathrm{DR}}$; ref. 42 for $K_{\mathrm{v}} 1$ and ref. 36 for $\mathrm{CaP} / \mathrm{Q}$ ):

$$
\begin{aligned}
& \frac{\mathrm{d} m_{\mathrm{soma}}}{\mathrm{d} t}=\frac{m_{\infty \text { soma }}-m}{m_{\zeta \text { soma }}} \quad m_{\infty \text { soma }}=\frac{1}{1+e^{(0.17 \times(-29.7-V))}} \quad m_{\zeta \text { soma }}=\frac{1}{\frac{0.182 \times(V+43)}{1-e^{-(V+43) / 6}-\frac{0.124 \times(V+43)}{1-e^{(V+43) / 6}}}} \\
& \frac{\mathrm{d} h_{\text {soma }}}{\mathrm{d} t}=\frac{h_{\infty \mathrm{soma}}-h}{h_{\zeta \mathrm{soma}}} \quad h_{\infty \text { soma }}=\frac{1}{1+e^{(-0.14 \times(-67-V))}} \quad h_{\zeta \text { soma }}=\frac{1}{\frac{0.024 \times(V+50)}{1-e^{-(V+50) / 5}-\frac{0.0091 \times(V+75)}{1-e^{(V+75) / 5}}}} \\
& \frac{\mathrm{d} m_{\text {axon }}}{\mathrm{d} t}=\frac{m_{\times \text {axon }}-m}{m_{\zeta \text { axon }}} \quad m_{\infty \mathrm{axon}}=\frac{1}{1+e^{[0.17 \times(-43.9-V))}} \quad m_{\zeta \text { axon }}=\frac{1}{\frac{0.182 \times(V+43)}{1-e^{-(V+43) / 6}-\frac{0.124 \times(V+43)}{1-e^{(V+43) / 6}}}}
\end{aligned}
$$

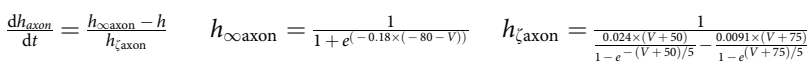

$$
\begin{aligned}
& \frac{\mathrm{d} n}{\mathrm{~d} t}=\frac{n_{\infty}-n}{n_{\zeta}} \quad n_{\infty}=\frac{1}{1+e^{(0.114 \times(13-V))}} \quad n_{\zeta}=\frac{e^{-(V-13) / 12.2}}{\left(1+e^{-(V-13) / 8.55}\right) \times 0.02} \\
& \frac{\mathrm{d} p}{\mathrm{~d} t}=\frac{p_{\infty}-p}{p_{\zeta}} \quad p_{\infty}=\frac{1}{1+e^{(0.07 \times(-17.5-v))}} \quad p_{\zeta}=2 \\
& \frac{\mathrm{d} k}{\mathrm{~d} t}=\frac{k_{\infty}-k}{k_{\zeta}} \quad k_{\infty}=\frac{1}{1+e^{(-0.18 \times(-72.7-v))}} \quad k_{\zeta}=2,000 \\
& \frac{\mathrm{d} r}{\mathrm{~d} t}=\frac{r_{\infty}-r}{r_{\zeta}} \quad r_{\infty}=\frac{1}{1+e^{(0.14 \times(-3.9-v))}} \quad r_{\zeta}=\frac{1}{1.2 \times \mathrm{e}^{V / 311.5}-0.14 \times e^{-V / 8.6}}
\end{aligned}
$$

where $V$ is the membrane potential of the simulated neuron. The equilibrium potentials for $\mathrm{Na}^{+}, \mathrm{K}^{+}, \mathrm{Ca}^{2+}$ and passive channels were set to $+93,-105$, +130 and $-50 \mathrm{mV}$, respectively. The conductance density is provided in Supplementary Table 1.

The resting membrane potential was set to $-78 \mathrm{mV}$ in control condition and to $-93 \mathrm{mV}$ for the hyperpolarized state. These variations in somatic resting potential propagated along the axon with a space constant of $200 \mu \mathrm{m}$.

Model of neuronal network. We developed a model of neuronal network inspired by the model described in ref. 43 (https://senselab.med.yale.edu; Model DB accession no. 138421). Here the conductance values in pyramidal neurons were replaced by our $\mathrm{Na}_{\text {Soma }}$ and $K_{\mathrm{DR}}$ conductance values (see above). The reversal potential for $\mathrm{GABA}_{\mathrm{A}}$ was set to $-80 \mathrm{mV}$ (ref. 44). This value is a hyperpolarized estimate of $\mathrm{EGABA}_{\mathrm{A}}$ but is still in the physiological range.

The connections between pyramidal neurons (e-cells, e) and interneurons (i-cells, i) are described by two parameters, respectively, the probability of connection between the different cells, $p$, and the strength of connection, $g_{-}$hat. In our model, these parameters were set as $p_{-}$ee $=1, \mathrm{p} \_\mathrm{e} i=1, \mathrm{p} \_\mathrm{ie}=0.5, \mathrm{p} \_\mathrm{ii}=1 ; g \_$hat_ee varying from 2 to $3.6 \mathrm{mS}, g \_h a t \_$ei $=1 \mathrm{mS}$, g_hat_ie $=1.8 \mathrm{mS}$ and $g$ hat $\_\mathrm{ii}=0.5 \mathrm{mS}$.

The network was driven by one stochastic input on e-cells and one on i-cells. Stochastic inputs are characterized by their frequency $f_{-} s t o c h$, their strength $g \_s t o c h$ and their decay time tau_d_stoch. We used $f$ stoch_e $=10 \mathrm{~Hz}$, $g \_s t o c h \_\mathrm{e}=0.5 \mathrm{mS}$, tau_d_stoch_e $=3 \mathrm{~ms}$ and $f_{-}$stoch_i $=5 \mathrm{~Hz}, g_{-}$stoch_i $=0.1 \mathrm{mS}$, tau d stoch_i $\mathrm{i}=3 \mathrm{~ms}$ for stochastic inputs on $\mathrm{e}$ - and $\mathrm{i}$-cells, respectively.

Simulations ran for 1-s duration, with a time interval of $0.02 \mathrm{~ms}$. To set the h-ADF rule, we saved the voltage of each cell in an independent matrix and multiplied it by the equation: $Y=0.9865+0.2489 /(1+\exp (-(\mathrm{V} 17+78.31) /-2.45))$. $Y$ being the h-ADF multiplier depending on V17, the voltage of the cell was $17 \mathrm{~ms}$ before the spike. The excitatory synaptic input between e-cells was then multiplied by this factor.

We ran 20 simulations for every value of $g \_h a t \_e e$ from 2 to $3.6 \mathrm{mS}$, and then calculated the coefficient of synchronization for every rastergram obtained. The coefficient of synchronization $k(\tau)$ was calculated as described in ref. 45 as an average value of coefficients $k_{\mathrm{i}, \mathrm{j}}(\tau)$ for each pair of e-cells $(\mathrm{i}, \mathrm{j})$ in the network. The time window was divided into bins of $\tau=1 / f_{\text {network }}$, with $f_{\text {network }}$ as the average frequency of the network, and APs were represented in a binary format (spike/no-spike pattern).

The network simulation was run on Matlab 2011 (MathWorks), and analysis of the coefficient of synchronization was performed with the custom software written in Labview 2010 (National Instruments).

\section{References}

1. Shimahara, T. \& Tauc, L. Multiple interneuronal afferents to the giant cells in Aplysia. J. Physiol. 247, 299-319 (1975).

2. Shimahara, T. \& Peretz, B. Soma potential of an interneurone controls transmitter release in a monosynaptic pathway in Aplysia. Nature 273, 158-160 (1978).
3. Nicholls, J. \& Wallace, B. G. Modulation of transmission at an inhibitory synapse in the central nervous system of the leech. J. Physiol. 281, 157-170 (1978).

4. Shapiro, E., Castellucci, V. F. \& Kandel, E. R. Presynaptic membrane potential affects transmitter release in an identified neuron in Aplysia by modulating the $\mathrm{Ca}^{+}{ }^{+}$and $\mathrm{K}^{+}$currents. Proc. Natl Acad. Sci. USA 77, 629-633 (1980).

5. Shu, Y., Hasenstaub, A., Duque, A., Yu, Y. \& McCormick, D. A. Modulation of intracortical synaptic potentials by presynaptic somatic membrane potential. Nature 441, 761-765 (2006).

6. Kole, M. H., Letzkus, J. J. \& Stuart, G. J. Axon initial segment Kv1 channels control axonal action potential waveform and synaptic efficacy. Neuron 55, 633-647 (2007).

7. Zhu, J., Jiang, M., Yang, M., Hou, H. \& Shu, Y. Membrane potential-dependent modulation of recurrent inhibition in rat neocortex. PLoS Biol. 9, e1001032 (2011).

8. Christie, J. M., Chiu, D. N. \& Jahr, C. E. Ca( $\left.2^{+}\right)$-dependent enhancement of release by subthreshold somatic depolarization. Nat. Neurosci. 14, 62-68 (2011).

9. Bouhours, B., Trigo, F. F. \& Marty, A. Somatic depolarization enhances GABA release in cerebellar interneurons via a calcium/protein kinase C pathway. J. Neurosci. 31, 5804-5815 (2011).

10. Alle, H. \& Geiger, J. R. Combined analog and action potential coding in hippocampal mossy fibers. Science 311, 1290-1293 (2006).

11. Scott, R., Ruiz, A., Henneberger, C., Kullmann, D. M. \& Rusakov, D. A. Analog modulation of mossy fiber transmission is uncoupled from changes in presynaptic Ca2 ${ }^{+}$. J. Neurosci. 28, 7765-7773 (2008).

12. Sasaki, T., Matsuki, N. \& Ikegaya, Y. Effects of axonal topology on the somatic modulation of synaptic outputs. J. Neurosci. 32, 2868-2876 (2012).

13. Bialowas, A. et al. Analog modulation of spike-evoked transmission in CA3 circuits is determined by axonal Kv1.1 channels in a time-dependent manner. Eur. J. Neurosci. 41, 293-304 (2015).

14. Awatramani, G. B., Price, G. D. \& Trussell, L. O. Modulation of transmitter release by presynaptic resting potential and background calcium levels. Neuron 48, 109-121 (2005).

15. Debanne, D., Bialowas, A. \& Rama, S. What are the mechanisms for analogue and digital signalling in the brain? Nat. Rev. Neurosci. 14, 63-69 (2013).

16. Shu, Y., Yu, Y., Yang, J. \& McCormick, D. A. Selective control of cortical axonal spikes by a slowly inactivating $\mathrm{K}^{+}$current. Proc. Natl Acad. Sci. USA 104, 11453-11458 (2007).

17. Shu, Y., Duque, A., Yu, Y., Haider, B. \& McCormick, D. A. Properties of action-potential initiation in neocortical pyramidal cells: evidence from whole cell axon recordings. J. Neurophysiol. 97, 746-760 (2007).

18. Engel, D. \& Jonas, P. Presynaptic action potential amplification by voltagegated $\mathrm{Na}^{+}$channels in hippocampal mossy fiber boutons. Neuron 45, 405-417 (2005).

19. $\mathrm{Hu}, \mathrm{W}$. et al. Distinct contributions of $\mathrm{Na}(\mathrm{v}) 1.6$ and $\mathrm{Na}(\mathrm{v}) 1.2$ in action potential initiation and backpropagation. Nat. Neurosci. 12, 996-1002 (2009).

20. Schmidt-Hieber, C. \& Bischofberger, J. Fast sodium channel gating supports localized and efficient axonal action potential initiation. J. Neurosci. 30, 10233-10242 (2010).

21. Debanne, D. et al. Paired-recordings from synaptically coupled cortical and hippocampal neurons in acute and cultured brain slices. Nat. Protoc. 3, 1559-1568 (2008).

22. Jones, H. C. \& Keep, R. F. Brain fluid calcium concentration and response to acute hypercalcaemia during development in the rat. J. Physiol. 402, 579-593 (1988).

23. Niespodziany, I. et al. Brivaracetam differentially affects voltage-gated sodium currents without impairing sustained repetitive firing in neurons. CNS Neurosci. Ther. 21, 241-251 (2015).

24. Madeja, M. Do neurons have a reserve of sodium channels for the generation of action potentials? A study on acutely isolated CA1 neurons from the guinea-pig hippocampus. Eur J. Neurosci. 12, 1-7 (2000).

25. Boudkkazi, S., Fronzaroli-Molinieres, L. \& Debanne, D. Presynaptic action potential waveform determines cortical synaptic latency. J. Physiol. 589, 1117-1131 (2011).

26. Takeuchi, A. \& Takeuchi, N. Electrical changes in pre- and postsynaptic axons of the giant synapse of Loligo. J. Gen. Physiol. 45, 1181-1193 (1962).

27. Thio, L. L. \& Yamada, K. A. Differential presynaptic modulation of excitatory and inhibitory autaptic currents in cultured hippocampal neurons. Brain Res. 1012, 22-28 (2004).

28. Cowan, A. I. \& Stricker, C. Functional connectivity in layer IV local excitatory circuits of rat somatosensory cortex. J. Neurophysiol. 92, 2137-2150 (2004).

29. Gong, B., Rhodes, K. J., Bekele-Arcuri, Z. \& Trimmer, J. S. Type I and type II $\mathrm{Na}\left({ }^{+}\right)$channel alpha-subunit polypeptides exhibit distinct spatial and temporal patterning, and association with auxiliary subunits in rat brain. J. Comp. Neurol. 412, 342-352 (1999).

30. Liao, Y. et al. Molecular correlates of age-dependent seizures in an inherited neonatal-infantile epilepsy. Brain 133, 1403-1414 (2010). 
31. Nigro, M. J., Quattrocolo, G. \& Magistretti, J. Distinct developmental patterns in the expression of transient, persistent, and resurgent $\mathrm{Na}^{+}$currents in entorhinal cortex layer-II neurons. Brain Res. 1463, 30-41 (2012).

32. Gutzmann, A. et al. A period of structural plasticity at the axon initial segment in developing visual cortex. Front Neuroanat 8, 11 (2014).

33. Colbert, C. M. \& Pan, E. Ion channel properties underlying axonal action potential initiation in pyramidal neurons. Nat. Neurosci. 5, 533-538 (2002).

34. Christie, J. M. \& Jahr, C. E. Selective expression of ligand-gated ion channels in L5 pyramidal cell axons. J. Neurosci. 29, 11441-11450 (2009).

35. Kim, S. Action potential modulation in CA1 pyramidal neuron axons facilitates OLM interneuron activation in recurrent inhibitory microcircuits of rat hippocampus. PLoS ONE 9, el13124 (2014).

36. Bischofberger, J., Geiger, J. R. \& Jonas, P. Timing and efficacy of Ca2 ${ }^{+}$channel activation in hippocampal mossy fiber boutons. J. Neurosci. 22, 10593-10602 (2002).

37. Berger, C., Meyer, E. M., Ammer, J. J. \& Felmy, F. Large somatic synapses on neurons in the ventral lateral lemniscus work in pairs. J. Neurosci. 34, 3237-3246 (2014).

38. Cobb, S. R., Buhl, E. H., Halasy, K., Paulsen, O. \& Somogyi, P. Synchronization of neuronal activity in hippocampus by individual GABAergic interneurons. Nature 378, 75-78 (1995)

39. Boudkkazi, S. et al. Release-dependent variations in synaptic latency: a putative code for short- and long-term synaptic dynamics. Neuron 56, 1048-1060 (2007).

40. Major, G., Larkman, A. U., Jonas, P., Sakmann, B. \& Jack, J. J. Detailed passive cable models of whole-cell recorded CA3 pyramidal neurons in rat hippocampal slices. J. Neurosci. 14, 4613-4638 (1994).

41. Lazarewicz, M. T., Migliore, M. \& Ascoli, G. A. A new bursting model of CA3 pyramidal cell physiology suggests multiple locations for spike initiation. Biosystems 67, 129-137 (2002).

42. Yang, J. et al. Dopaminergic modulation of axonal potassium channels and action potential waveform in pyramidal neurons of prefrontal cortex. J. Physiol. 591, 3233-3251 (2013).

43. Kopell, N., Börgers, C., Pervouchine, D., Malerba, P. \& Tort, A. in Hippocampal Microcircuits. (ed. C., V.) (Springer, 2010).

44. Tyzio, R., Holmes, G. L., Ben-Ari, Y. \& Khazipov, R. Timing of the developmental switch in GABA(A) mediated signaling from excitation to inhibition in CA3 rat hippocampus using gramicidin perforated patch and extracellular recordings. Epilepsia 48 (Suppl 5): 96-105 (2007).

45. Pavlov, I. et al. Tonic GABAA conductance bidirectionally controls interneuron firing pattern and synchronization in the CA3 hippocampal network. Proc. Natl Acad. Sci. USA 111, 504-509 (2014).

\section{Acknowledgements}

This study was supported by the Institut National de la Santé et de la Recherche Médicale, Centre National de la Recherche Scientifique, Agence Nationale de la Recherche (ANR Blanc 'REPREK'-11-BSV4-016-01 and ANR Santé \& Bien-Etre 'AXODE'-14-CE13-0003-02), Fondation pour la Recherche Médicale (doctoral grant FDT-2011-0922774 to A.B., postdoctoral grant SPF-2011-1223409 to V.M. and grant DSV-2013-1228768 to D.D.), the Ecole Normale Supérieure (doctoral grant to M.Z.) and the French Ministry of Research (doctoral grant to A.B.). We thank L.P. Savtchenko and J.M. Goaillard for helpful discussion, M. Seagar for comments on the manuscript, B. Mazet for help with Matlab and N. Boumedine for excellent technical assistance.

\section{Author contributions}

S.R. and M.Z. conceived the project, performed the experiments and analysis, developed computer simulations (single neuron and network) and wrote the manuscript. A.B. conceived the project and performed the experiments and analysis. V.M. conceived the project and performed the experiments and analysis. N.A. performed computer simulations (single neuron). E.C. and L.F.-M. performed the experiments and analysis, D.D. conceived the project, analysed the data and wrote the manuscript.

\section{Additional information}

Supplementary Information accompanies this paper at http://www.nature.com/ naturecommunications

Competing financial interests: The authors declare no competing financial interests.

Reprints and permission information is available online at http://npg.nature.com/ reprintsandpermissions/

How to cite this article: Rama, S. et al. Presynaptic hyperpolarization induces a fast analogue modulation of spike-evoked transmission mediated by axonal sodium channels. Nat. Commun. 6:10163 doi: 10.1038/ncomms10163 (2015).

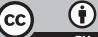

This work is licensed under a Creative Commons Attribution 4.0 International License. The images or other third party material in this article are included in the article's Creative Commons license, unless indicated otherwise in the credit line; if the material is not included under the Creative Commons license, users will need to obtain permission from the license holder to reproduce the material To view a copy of this license, visit http://creativecommons.org/licenses/by/4.0/ 